\title{
Die geestelike aard van die kerklike tug soos in gereformeerde kerkordes
}

\author{
Strauss, Piet \\ Universiteit van die Vrystaat \\ straussp@ufs.ac.za ${ }^{1}$
}

\begin{abstract}
The spiritual character of church discipline

This article focuses on the meaning of the words "the spiritual character of church discipline" used in the Church Order of Dordrecht in 1619 and since then in the church orders of churches with an affinity for the Church Order of Dordt.

The conclusion is that the aim, way of implementation and climate of church discipline combined with other considerations in reformed church government all help to clarify the spiritual character of church discipline. At the basis of it the spiritual character of this kind of discipline is determined by the spiritual discipline of the Word and Spirit of God. In this regard inner convictions and not physical force or a technical application of church order measures must determine the acts of church discipline. Steps which should also be spiritual in nature.

Church discipline should be in obedience to the Head of the church, Jesus Christ. He governs the church through His Word.
\end{abstract}

Key words

Die Dordtse kerkorde; Gereformeerdheid; Kerkreg; kerklike tug; geestelike aard

\section{1. 'n Duidelike lyn in gereformeerde kerkordes: Probleemstelling}

Kerke wat kerkordelik in die Dordtse tradisie staan, vertoon normaalweg elemente van die Dordtse Kerkorde van 1619 (DKO 1619) in hulle eie

1 Prof Piet Strauss is sedert sy aftrede in 2014 'n navorsingsgenoot in die Departement van Historiese en Konstruktiewe Teologie (Ekklesiologie), Fakulteit Teologie, Universiteit van die Vrystaat, Bloemfontein. 
kerkordes. Hierdie elemente kom in verskillende kerkordes in verskillende gedaantes na vore. Die DKO vorm die eind- of kulminasiepunt van die kerkordelike ontwikkeling in die Gereformeerde Kerk in Nederland van die $16^{\mathrm{e}}$ en $17^{\mathrm{e}}$ eeue (vgl Rutgers 1971; Pont 1981:19-188).

Die invloed van die DKO 1619 blyk uit sake soos die hoofstukindeling en sekere artikels, beginsels en verwoordings in die kerkordes van resente gereformeerde kerke (vgl die DKO in Pont 1981:176-186 met Visser 1999; Engelhard en Hofman 2001 en Die Kerkorde van die Ned Geref Kerk of NGKO 2013).

In sy $17^{\text {de }}$ eeuse Nederlands praat die DKO van die "Christelijke straf" of "kerklijke censuren" of, soos dit tans genoem word, kerklike tug as "geestelijk" (afgedruk in Pont 1981:184; vgl Jansen 1952:302). Volgens die DKO moet hierdie tug van die "burgerlijke gericht of straf der overheid" onderskei word. Op dié twee punte - die kerklike tug wat geestelik is én wat van die straf van die staat onderskei moet word - volg daar sedertdien wye navolging onder gereformeerdes in die Dordtse tradisie.

Die Kerkorde van die Gereformeerde Kerke in Suid-Afrika (GKSA-KO) stel dit - soos die DKO - in sy artikel 71 dat die "kerklike tug... geestelik" is (afgedruk in Kruger et al 1966:423; Visser 1999:261). Die uitleg en samestelling van die GKSA-KO dui daarop dat dit op die spoor van die DKO in die hede wil loop (Kruger et al 1966:40). 'n Eertydse Kerkorde van die Christian Reformed Church (CRC-KO, Noord-Amerika) praat in sy artikel 78 die DKO tot 'n groot mate na as hy sê: "the admonition and discipline of the church are spiritual in character and therefore require the use of spiritual means" (afgedruk in Van Dellen en Monsma 1967:288). 'n Hersiene CRC-KO (afgedruk in Engelhard en Hofman 2001:11) gebruik in sy bepalings vir kerkvergaderings wat tug toepas uitdrukkings soos dat die vergaderings moet "assure that adequate pastoral care" en "a spirit of love and openness" daarmee gepaard gaan (Engelhard en Hofman 2001:429, 437). Daarmee volg hierdie CRC-KO ook die lyn dat die kerklike tug geestelik van aard is.

Die vertrekpunte vir die kerklike tug in die kerkorde van 1959 van die destydse Gereformeerde Kerke in Nederland (GKN-KO 1959) en sommige van hulle tydgenote stem tot 'n groot mate ooreen. Die GKN-KO noem die aard van die kerklike vermaning en "tucht" "geestelijk". Die CRC-KO van 
voor 1967 sluit woordeliks hierby aan en interpreteer, soos die GKN-KO, die DKO in eietydse terme as hy daarop laat volg dat die tug met geestelike middele en die vermyding van "wereldse machtsoefening" uitgeoefen moet word (die GKN-KO by Nauta 1971:358; die CRC-KO by Van Dellen en Monsma 1967:288). Die CRC-KO stem op punte dus ooreen met die GKN$\mathrm{KO}$, maar gebruik ook die uitstaande elemente in die DKO naamlik dat die tug geestelik van aard is en 'n ander aard as die straf van die staat het. Bygesê, die GKN-KO 1959 wou uitdruklik 'n eietydse weergawe van die DKO wees (Strauss 2010:8) en het as sodanig die CRC-KO - klaarblyklik ook beïnvloed.

Die eerste Kerkorde van die eerste Algemene Sinode van die Ned Geref Kerk van 1962 (NGKO 1962), gebruik die GKN-KO 1959 as basis om ook die DKO “aangepas by die eise van ons dag" te wees (Vorster 1960:13). NGKO 1962 artikel 57 bepaal prontuit dat die "kerklike opsig en tug 'n geestelike karakter dra” (NGKO 1964:12). Meer as 50 jaar later gebruik NGKO 2013 artikel 60.1 dieselfde uitgangspunt as hy aanvoer dat die "kerklike opsig en tug ... 'n geestelike karakter (dra) en pas by die kerk as 'n geloofs- en liefdesgemeenskap" (NGKO 2013:16).

Die geestelike karakter van die kerklike tug is dus 'n erkende, gevestigde begrip in gereformeerde kerke met 'n Dordts-gereformeerde "konneksie". 'n Konneksie met die Dordtse Sinode van 1618-1619 wat deur HH Kuyper aan die einde van die $19^{\text {de }}$ eeu bestempel is as "het Gereformeerde oecumeniesche concilie" omdat dit op daardie stadium die enigste een van sy soort was (Kuyper sa:vi). Die ekumeniese karakter van die Sinode blyk uit die feit dat afgevaardigdes van gereformeerde kerke in Nederland, Engeland, Duitsland en Switserland hier teenwoordig was. As 'n tipiese ekumeniese saak wat al die deelnemende kerke rak, het die Sinode die Drie Formuliere van Eenheid as belydenisskrifte aanvaar waaronder ook die Dordtse Leerreëls (chronologies die derde van die Drie Formuliere ${ }^{2}$ ) wat hyself pas opgestel het. Die DKO is deur die Nederlandse afgevaardigdes alleen gefinaliseer (Kuiper 1995:268).

2 Die Nederlandse Geloofsbelydenis kom in 1561, die Heidelbergse Kategismus in 1563 en die Dordtse Leerreëls by die Nasionale Sinode van Dordrecht in 1618-1619, Jonker 1994:50,92,126. 
Die vraag wat hierdie artikel ondersoek is: wat moet die inhoud van die geestelike aard van die kerklike tug wees? Waarom handhaaf soveel gereformeerde kerke hierdie uitgangspunt? Kerkordes, skrywers en gebeure word ondersoek en 'n eie standpunt ontwikkel.

In sy studie van die kerklike tughandeling wys Sadler daarop dat die geestelike karakter daarvan noodsaaklik is om die kerklike tug in sy doel te laat slaag. Die doel van die tughandeling is immers ook geestelik van aard. Daarom is kerklike tug ook ala Calvyn gerig op die eer van God, die heil van die gemeente (kerk) en die (geestelike) behoud van die sondaar (Sadler 1979:9; vgl Sizoo sa:260-262; Van Dellen en Monsma 1967:291; Nauta 1971:348; NGKO 2013:16).

Sadler voer aan dat die geestelike karakter van die kerklike tug "op verskillende wyses" tot openbaring kom. Calvyn het die geestelike aard van die tughandeling - die praktyk van die kerklike tug - gesoek in die manier waarop die Woord van God daarin funksioneer, die gees waarin dit geskied, die sake waaroor dit gaan en die persone wat daarin die leiding neem (Sadler 1919:9). Hierdie geestelike aard word nou dieper ondersoek: in kerkordes en ander bronne.

\section{Kerkordes oor die geestelike aard van die kerklike tug}

Die DKO self gee nie 'n detailbeskrywing van die geestelike aard van die kerklike tughandeling nie.

Wat die DKO wel aandui, is dat die kerklike tug van die dwingende straf van die staat onderskei moet word en dat kerklike tug die skuldiges nie van die straf van staatsinstansies vryspreek of dit moet ondermyn nie. Vir die DKO is die doel van die kerklike tug geestelik en daarom koppel hy dit aan twee geestelike mikpunte: die versoening van die sondaar met sy naaste en die verwydering van 'n "ergernis" ('n emosionele gevolg) uit die kerk of gemeente (afgedruk in Pont 1981:184). Die implikasie hiervan is dat slegs daardie beweerde oortredings wat 'n openlike "ergernis" of aanstootlikheid in die kerk veroorsaak, tot 'n amptelike kerklike tugondersoek moet lei. Die kerk kan nie 'n amptelike ondersoek loods na elke bakatel of geringe skeeftrap nie. Die kerk - soos die burgerlike hof - moet hom nie ophou met "beuselagtighede" nie. Kleiner sakies word meermale deur onderlinge gesprek in die reine gebring. 
Versoening vra vir 'n liefdes- en pastoraal-persoonlike benadering wat in elke geval eie moet wees aan die kerklike ampsbediening. Op sy beurt vra die verwydering van 'n openbare ergernis 'n verantwoorde ondersoek en 'n geopenbaarde bevinding. Aan die wortel hiervan lê die Bybelse oortuiging dat liefde en versoening sonder die waarheid nie haalbaar is nie.

Die DKO gee dus blyke van die gereformeerde oortuiging dat 'n kerkorde nie alles moet sê en bepaal nie, maar bloot koers aandui en daarvoor "weinig bepaald en omshreven" (Bouwman 1985:325-327). Dat kerkvergaderings soos Jonker dit stel - met die Bybel in die hand langs die "enkele groot lyne" van die kerkorde moet streef na 'n Christusregering in die kerk as 'n regering deur die Woord (Jonker 1960:36).

Enkele kerkordes in die Dordtse tradisie kom vervolgens aan die bod.

Die Kerkorde van die GKN van 1959 gebruik in sy artikel 71 'n woordelikse herhaling van die DKO artikel 71 (Jansen 1952:302; vgl Pont 1981:184). GKN-KO 1959 artikel 106 loop wesenlik dieselfde pad met die algemene, "nadere" reëling dat die kerklike tug op 'n "geestelijke wijze" met die "vermijding van alle wereldse machtsoefening" uitgeoefen moet word (Nauta 1971:358). Die "hoe" van hierdie geestelike wyse word nie bepaal nie, maar aan kerkvergaderings oorgelaat. 'n Vroeëre CRC-KO praat slegs van die geestelike aard en middele van die kerklike tug (Van Dellen en Monsma 1967:288). 'n Meer resente CRC-KO beskou eienskappe soos pastorale sorg en 'n gees van liefde en openhartigheid as deel van die geestelike karakter - die geestelike karakter word in hierdie CRC-KO geïmpliseer en nie verwoord nie - van die kerklike tug. Vir die CRC$\mathrm{KO}$ is die kerklike tug of "discipline" deel van die pastorale werk van die CRC as 'n geloofsinstelling (Engelhard en Hofman 2001:430). Volgens die CRC-Sinode van 1991 sluit hierdie pastorale benadering "Christian care and concern" in (Engelhard en Hofman 2001:438). Op sy beurt bepaal die GKSA-KO dat die "kerklike tug" geestelik en noodsaaklik is om die eer van God te handhaaf, "die sondaar met die kerk en sy naaste te versoen" en "die aanstoot" uit die gemeente weg te neem. In sy verklaring van die GKSA-KO sê Visser dat die geestelike aard van die kerklike tug 'n aanduiding is dat dit 'n liefdeshandeling of bewys van liefde is omdat die Here in die Woord aandui dat Hy diegene wat Hy liefhet, tugtig en kasty (Heb 12:6, Open 3:19: Visser 1999:262). Op hulle beurt voer Kruger et al aan dat die Christelike 
of kerklike karakter van die tug vereis dat dit in liefde toegepas word: liefde tot God, vir die sondaar en vir die kerk (Kruger et al 1966:426).

NGKO 2013 kleur sy verstaan van die geestelike karakter van die kerklike tug met meer besonderhede in. Ter aanvang bepaal NGKO 2013 ook dat die "kerklike tug opsig en geestelik" is en op 'n kerklike wyse met "geestelike middele" uitgeoefen moet word. Die tug met sy geestelike aard is immers 'n aanvaarde aspek van die bestaan van die kerk as 'n gehoorsame geloofsen liefdesgemeenskap in, let wel, die gebroke sondige wêreld. Daarom is die tug pastoraal-kerkregtelik (versorgend, koesterend én ingestel op regverdigheid en bekering van 'n aan-God-ongehoorsame optrede) van aard en moet dit uit 'n "Bybelse en geestelike oogpunt (ook) billik en regverdig toegepas word" (NGKO 2013:16). NGKO beskou die tug dus as 'n tipiese kerklike handeling wat billik en gegrond wil optree omdat die kerk - soos sy Here - liefhet. Die liefde vir God en mens kan ongehoorsaamheid aan God en daarmee onreg in hierdie sondige gebrokenheid, nie aanvaar nie.

Die geestelike karakter van die tug beteken dat dit gaan oor sake wat kerklik is of 'n kerklike aspek ('n geloofs- of etiese kant, vgl Nauta 1971:127) ontwikkel en daarmee die geloofsbelang van die kerk kruis en kerklike aandag vereis.

Uit hierdie kerkordes blyk dit dat die geestelike karakter van die kerklike tug bepaal word deur die doel van die tug én die wyse waarop die kerk of sy gemagtigde vergaderings dit uitoefen. 'n Bybelse versoening met jou naaste en 'n kerklike vry wees van aanstootlike sondes begin in die hart van die gelowige en word bewerk deur die oortuiging wat die Woord en Gees van God gee. Kerklike tug is geestelik omdat kerklike versoening, berou en bekering of 'n kerklike afwysing van ongehoorsaamheid aan God spruit uit die geestelike oortuiginge van die betrokkenes. As 'n geloofsinstelling werk die kerk met geloofs- en etiese oortuiginge. Daarom noem NGKO die kerk "'n geloofs- en liefdesgemeenskap" (NGKO 2013:16).

In hulle kommentaar op kerkordes en hulle bespreking van die geestelike karakter van die kerklike tug gaan enkele skrywers in meer besonderhede hierop in. 


\section{Skrywers oor die geestelike aard van die kerklike tug}

Sadler glo dat beskrywende woorde vir die kerklike tug soos "die toon van die burgerlike regspleging vermy", "opsieners wat hulself nooit as regters beskou nie" en "tug uit tere liefde en belangstelling" (NGKO 1964:12) inhoudlose slagspreuke word as dit nie met dade gepaard gaan nie.

So word

“die tughandeling 'n gereglementeerde tegniek waaruit die lewe verdwyn het en wat sy ware doel mis. Tug wat nie deur die sondaar as tug uit liefde ervaar word nie, en wat nie daarin slaag om hom bewus te maak dat dit God se handeling met hom is nie, is by voorbaat tot mislukking gedoem" (Sadler 1979:9).

Daarmee skep die kerklike tug die indruk van 'n menslike bemoeienis en menslike diskriminasie. Hierteenoor wys Sadler daarop dat Calvyn die geestelike aard van die tughandeling herken het aan die manier waarop die Woord daarin funksioneer, die gees waarin dit geskied, die sake waarin die kerk met bevoegdheid kan optree en die persone wat daarin die leiding neem (Sadler 1979:8).

Sadler brei verder op die gees van die tughandeling uit.

Tug is volgens hom deel van die vaderlike en moederlike taak ${ }^{3}$ van die kerk wat 'n kind van sy dwaalweg wil bekeer. 'n Deeglike ondersoek na die waarheid en 'n gegronde bevinding in die betrokke geval moet lei tot 'n volgende belangrike stap: "om met tere liefde en belangstelling die oortreders te probeer terugbring van hulle dwaalweë". Kerklike ondersoekers moenie haastig of oorywerig wees om 'n tugondersoek af te handel nie. Hulle moet geduldig wees en alles behoorlik uitpluis. Die ander kant van die saak alle kante - moet behoorlik aangehoor word. 'n Tugsaak moet ook nie onnodig sloer nie. 'n Heimlike sonde moenie noodwendig bekend gemaak word in die gemeente nie, want die liefde bedek volgens 1 Korintiërs 13:7 alles. Volharding in heimlike sondes kan dit egter wyer bekend laat word en tot openbare aanstoot lei. Sondaars wat onnadenkend of onverhoeds

3 Die NGKO 1962 praat van kerklike tug as 'n tug deur vaderlike opsieners (NGKO 1964:12) en Calvyn van die kerklike tug as die moederlike taak van die kerk wat versorg, bewaar en behou (Sizoo sa IV:10). 
oortree, moet sagmoedig reggehelp word. Die evangeliese gesindheid van die tughandeling vra beslistheid sonder oormatige strengheid. Kerklike ondersoekers moenie wanhoop aan die bereiking van die doel van die tug nie en die handeling met ootmoed voor God en deurlopende selftug verrig. Laastens - volgens Sadler - moet die kerklike tug liefdevol, maar ook "sonder aansiens des persoons" verrig word. Onpartydigheid teenoor die klaer en aangeklaagde moet gehandhaaf en mensevrees vermy word (Sadler 1979:13-14; vgl Calvyn in Sizoo sa:17; Plomp 1969:76).

Bouwman onderstreep die handhawing van die kerklike tug as een van die drie merktekens van die ware kerk: die Nederlandse Geloofsbelydenis artikel 29 se suiwere bediening van die Woord en die sakramente en die kerklike tug om die sonde te straf (NGK-Uitgewers III 1982:29). Vir Bouwman komplementeer hierdie drie mekaar. Tug beteken om - vanuit die Woord - nader te trek en op te voed. Dit gaan gepaard met teregwysings, vermanings en bestraffings en kan lei tot'n afsnyding van die gemeente. Die kerklike tug is volgens hom kerklik-geestelik en daarom van 'n persoonlike en 'n amptelike aard (Bouwman 1985: 598-599).

Jansen voer aan dat die woordjie "geestelik" in die DKO direk teenoor die uitwendige, dwingende mag en straf van die staat staan. God het dit aan die kerk gegee om die Woord, die sakramente en die tug te bedien. Hierdie middele werk geestelik of innerlik. Effektiewe kerklike tug werk met "zedelijke overtuiging..., vermaning en waarschuwing" - 'n saak wat uit die Nederlandse Geloofsbelydenis artikel 30 voortvloei. Hier word bely dat die kerk deur die "geestelijke politie" (bestuurswyse) wat van die Here kom, regeer moet word (NGK-Uitgewers III 1982:30). Jansen beskou die aanvaarde gereformeerd kerklike tugmaatreëls van vermaning, waarskuwing, onthouding van die sakramente en uitsluiting uit die gemeenskap van die gelowiges as geestelike middele wat moet oortuig. Hy is ook 'n voorstander van 'n kerkorde wat nie 'n "afgewerkte systeem van tucht" gee nie, maar alleen die "hoofdlijnen" uitstippel waarlangs die kerklike tug toegepas moet word. 'n Tug wat ten diepste Woordtug is en met liefde en diskresie uitgeoefen moet word (Jansen sa:127-135).

Nauta sluit later hierby aan as hy die geestelike bestuurswyse van die kerk naamlik om te werk deur oortuiging, ook in verband bring met die geestelike aard van die kerklike tug. Volgens hom moet die kerklike tug en vermaning 
om te slaag die gewetens van die teikengehoor oortuigend aanspreek. Tot so 'n mate dat hulle daardeur in die hart geraak word, tot bekering kom en die "gedragslijn, die tot dat vermaan en de tucht aanleiding gaf", verander. Die geestelike karakter van die kerklike tug vereis wysheid en groot geduld waardeur mense nie deur menslike voorkeure nie, maar die Woord van God aangespreek word. Die tug moet van so 'n aard wees dat dit mense oortuig dat hulle hul deur die wil van "hun enige en volstrekte Heer, Jesus Christus... laten gezeggen". Nauta vind die geestelike karakter van die kerklike tug in Filippense 2:1-4. Hier lei geestelike gemeenskap, ontferming en barmhartigheid teenoor mekaar die gemeente om eensgesind te wees: een in liefde, een van hart en een in strewe - sonder selfsug of eiebelang met 'n strewe na mekaar se belange (Nauta 1971:358-359; vgl Fil 2:1-4).

Visser handhaaf die inkleding van hierdie geestelike lyn as hy daarop wys dat die kerklike tug van die "burgerlike straf" onderskei moet word. Ook hy sien die geestelike karakter van die tug in vermaning, bestraffing, die opskorting van kerklike gemeenskap en by die "uiterste verharding uitbanning uit die gemeente" (Visser 1999:262).

Smit noem God se reg vir sondaars wat dit nie verdien nie 'n verlossende, toegekende geregtigheid om Christus ontwil, 'n "compassionate justice". Vir Smit is God in sy geregtigheid bekommerd oor die verlossing, genesing, herstel en redding van die slagoffers van die gebrokenheid en oor diegene wat vergifnis, nuwe geleenthede en 'n tweede kans of 'n herstelde lewe nodig het. Die Here se verlossende geregtigheid is 'n omgeeen genadige geregtigheid, 'n bewys van sy trou aan sy beloftes gemaak in sy genadeverbond (Smit 2009:377). As dieselfde God tugtig omdat Hy liefhet, moet die geestelike karakter van die kerklike tug sy "compassionate justice" as een van sy eienskappe kommunikeer. Daarom is die doel van die kerklike tug nie om uit te ban of weg te dryf nie, maar soos Bouwman dit stel, “... om te trekken” (Bouwman 1985:598).

Uit die relaas tot dusver blyk dit dat die geestelike karakter van die kerklike tug na vore kom in die feit dat dit gegrond word op die tugtiging van die Here omdat Hy liefhet, 'n liefde wat prakties ook moet deurkom in die doel van die tug sowel as die klimaat by die toepassing daarvan. Daar is ook ander sake rondom die kerk - in die konteks van die Christelike kerk - wat tot die geestelike aard van die kerklike tug bydra. 


\section{Ander aspekte rondom die geestelike aard van die kerklike tug}

Bouwman verbind die opdrag aan die kerk tot tug met die geestelike karakter van die koninklike amp van sy Hoof, Jesus Christus. Die kerk het sy ontstaan en verlossing aan Christus te danke. Die lewe wat uit die opgestane (uit die geestelike en liggaamlike dood, vgl bv Johannes 2 en 1 Korintiërs 15, PS) Christus kom, is aan die kerk deur die Heilige Gees geskenk sodat dit as die liggaam van Christus "geheel en onvoorwaardelijk" aan Hom behoort en vir Hom moet lewe. Vir Bouwman as 'n kerkregtelike regeer Christus sy kerk direk of "rechstreeks van uit den hemel door zijn Geest en Woord" én indirek deur sy dienaars of ampsdraers (Bouwman 1985:600: vgl Coertzen 1998:9). Daarom is die kerklike tug 'n uitvloeisel van die werk van Christus in sy kerk as - soos Sondag 12 van die Heidelbergse Kategismus dit uitdruk - "ons ewige Koning wat ons met sy Woord en Gees regeer en ons by die verlossing (van sondeskuld en -smet) wat verwerf is, beskerm en bewaar" (Bouwman 1985:600; NGK-Uitgewers III 1982:47). Christus heers as Koning deur sy Woord en Gees oor die voortdurende ongehoorsaamheid in sy kerk (Efesiërs 4:17-24) as - op hulle beste begenadigde, gelowige sondaars. ${ }^{4}$ 'n Heerskappy van die Heilige Gees (die Gees van Christus) deur die Woord wat geestelik van aard is en deur oortuiging werk. 'n Heerskappy waarin die kerklike tug gehoorsaamheid aan Woord en Gees van God is wat oortuiging gelowige sondaars aan die Woord bind.

Jansen wat die kerklike tug van staatsdwang en -straf onderskei, glo dat die kerklike tug geen dwang of straf is nie, maar "langs den weg van zedelijke overtuiging, door vermaning en waarschuwing, zoeken te winnen". Hy noem dwang 'n maatreël wat onwilliges dwing of verplig om hulle - teen hulle sin - aan die wet te onderwerp en straf die herstel van die reg of regsorde deur die strafmaatreël. Omdat die kerk lidmate deur die Woord en Gees, deur oortuiging, aan 'n sekere leefstyl bind, kan hy nie dwing nie (Jansen sa:128-129). Wat Jansen egter uit die oog verloor, is dat die dwang van die Heilige Gees deur die Woord of deur oortuiging sterker is as staatswang omdat dit nie fisies dwingend nie, maar geestelik

4 Martin Luther het daarop gewys dat 'n begenadigde sondaar nie 'n sondelose verloste is nie, maar 'n "simul justus ac peccator", 'n geregverdigde, vrygespreekte sondaar, De Jong 1987:170. 
dwingend is. Dwang op sigself is nie onbybels of onkerklik nie, omdat 'n geloofsoortuiging geestelik dwingend en daarby kerklik aanvaarbaar is. Daarby is dit sekerlik 'n vorm van tug of straf om iemand van sy kerklike voorregte soos die gebruik van die sakramente, te ontneem. As straf neerkom op die ontneming van die kerklike vryhede van mense of 'n openlike, afwysende waarskuwing aan sondaars oor hulle dade, is kerklike tugmaatreëls persoonlike en geestelike straf. Hierdie soort kerklike tugmaatreëls kan ook lei tot geestelike en persoonlike leed by mense. Dit is egter straf wat wil genees of herstel, 'n oorweging wat 'n burgerlike hof ook in ag neem. Sadler meen dat die weerstand teen tug as straf onder gereformeerdes 'n reaksie is op die Roomse en ander kerklike tuggebruike ${ }^{5}$ waarin geldboetes of fisiese kettings as boeie gebruik is (Sadler 1979:16-17).

Jansen is oortuig dat die kerklike tug geestelik is omdat dit "rechtstreeks van God als Vader van onzen Heere Jesus Christus" wat deur die Heilige Gees hierdie mag aan die kerk gegee het, afkomstig is. Die kerk het immers die opdrag van die Here om die Woord, die sakramente en die tug te bedien. 'n Opdrag wat Jansen neem uit Handelinge 20:28 en Efesiërs 4:11 (Jansen sa:131). Hy noem "kerkelijke tucht" 'n saak met "geestelijke macht". 'n Mag wat deur die Here van die kerk gesanksioneer is (Jansen sa:136).

Wat bydra tot die geestelike karakter van die kerklike tug, is die vereiste dat dit met toleransie gepaard moet gaan en nie te gou tot 'n bevinding moet kom nie. Die oorweging dat'n saak nie "alte haastig" afgehandel moet word nie. Daarom neem 'n kerklike tugsaak spreekwoordelik "altyd langer" en moet die ondersoekliggaam bereid wees om die tweede en derde myl met alle mense betrokke - die klaer(s), aangeklaagde(s) en getuies - te loop ten einde seker te maak van die inhoud van hulle bydraes en oortuiginge. Dit gaan hier immers om die eer van God. Sadler wys daarop dat die kerklike tug tolerant én intolerant moet wees. Hy bepleit 'n "mate van toleransie" maar beskou "n alte grote toleransie" as skadelik vir die kerk. Aan die een kant wys hy op die toleransie van 'n Eli wat sy 2 seuns met moord laat wegkom het en aan die anderkant op die Fariseërs vir wie die tug 'n maklike, ongekompliseerde saak was. Hierdie toleransie sluit volgens hom

5 In die vermenging van die belange van die Ned Geref Kerk en die Hollands-OosIndiese-Kompanjie aan die Kaap het die kerklike tug na 1652 soms die vorm van 'n terughou van die maandelikse salaris of 'n geboeiwees in kettings aangeneem, Strauss 2005:6,7. 
die benadering van alle moontlike openbare aanstootlike of tugwaardige sondes van leer en lewe in (Sadler 1979:21).

Sadler stuit hiermee op 'n tendens in kerke of gemeentes waarin dit by tugsake, verskille of geskille dikwels gelowiges is wat met mekaar moet versoen. 'n Versoening wat deur'n geduldige, omvattende gesprek moontlik is omdat die kern van hulle geloof en belydenis, van hulle oortuiging en benadering, ooreenstem. Omdat 'n oog tot oog gesprek tot die ontdekking kan lei dat die saak makliker oplosbaar is as wat gemeen is. Hierdie tendens het die Ned Geref Kerk genoop om dit in 2002 in sy kerkorde op te neem dat 'n klag, gerug of verslag wat tot 'n tugsaak kan lei, "waar toepaslik", eers deur middel van herderlike sorg, versoeningsaksies of die hantering daarvan as 'n geskil, hanteer kan word. Indien dié vooraf inisiatief nie die gewenste resultaat lewer nie, moet die saak voortgaan (NGKO 2002:25).

Nog 'n saak "rondom" die kerklike tug wat die geestelike aard daarvan versterk, is die tipering van die kerklike tughandeling as 'n quasi-judisiële handeling. Hierdie gemeenregtelike term impliseer dat die kerk in tugsake op die oog af met juridiese handelinge besig is, maar in wese nie 'n regsorgaan is nie. Tog is die kerk in sulke handelinge van owerheidsweë beskou gebonde aan die reëls van natuurlike geregtigheid wat regverdigheid van alle quasie-regshandelinge wil verseker. Die vier reëls wat wyd aanvaar word, is die audi alteram partem-reël (die ander kant van die saak moet ook gehoor word), die nemo iudex in causa sua-reël (niemand is regter in sy eie saak nie), onpartydigheid en 'n behoorlike aandagbesteding aan die saak (Strauss 2010:112). Hierdie reëls berus op billikheidsoorwegings én stem ooreen met Skrifbeginsels (Sadler 1979:51; vgl Du Plooy 2007:18vv, Coertzen 2003:210).

Liefde vereis regverdigheid en daarom kan kerke - die howe kan dit in hulle hersiening van kerklike uitsprake afdwing - hierdie reëls aanvaar (NGKO 2013:16). Liefde met regverdigheid verhoog die billike en daarmee geestelike karakter van die kerklike tug.

\section{Die geestelike aard van die kerklike tug: Samevatting}

Teen hierdie agtergrond kan die geestelike karakter van die kerklike tug uit 'n Dordts-gereformeerde hoek duideliker bepaal en saamgevat word. 
Die eerste oorweging waarom die aard van die kerklike tug geestelik is en moet wees, is die feit dat God Drie-enig deur die bemiddeling van Jesus Christus en die werk van die Heilige Gees die Oorsprong en Onderhouer van die kerk is. Die kerk as 'n geloofsgemeenskap wat bestaan uit belydende gelowiges en hulle gedoopte kinders, werk met oortuiging deur die Woord van God as die swaard van die Gees (Ef 6:17) en die werksmetode van die Christelike geloof. Hierdie norm sluit die dwingende, fisiese aard van die straf van staatsinstellings én die misbruik van die tugprosedure vir oorwinnings op tegniese "punte", uit. Kerklike tug as 'n geestelike handeling strewe na die oortuiging en nie die manipulering, tegniese lamlê of emosionele oordondering van die betrokkenes nie.

Die tweede oorweging waarom die kerklike tug geestelik van aard moet wees, spruit uit die doel van die kerklike tug. Hierdie doel is die herstel van die kerk as 'n Christelike geloofseenheid of 'n -verband. NGKO 2013 noem die doel van die tug die eer van God, die heil van die gemeente of kerk en die behoud van die sondaar (NGKO 2013:16). As die kerklike tug bly by sy doel, verhoog hierdie aksie sy geestelike karakter.

Die derdeoorweging waarom die aard van die kerklike tughandelinggeestelik moet wees, is omdat die kerk self 'n geestelike, geloofs- en liefdesinstelling is. Daarom speel eerlikheid, liefde, geduld en toleransie, beslistheid sonder kilheid of haastigheid en die deurwerking van die kernbeginsels van die Christelike geloof, almal 'n rol in die kerklike tughandeling. Kerklike tug is veel eerder 'n interne familie ondersoek gerig op die eer van God as Vader van almal as 'n eksterne, saaklike, regterlike verhoor. Kerklike tug raak die geloofsemosies van die klaer(s) of aandraer(s) van 'n nadelige gerug of verslag, die aangeklaagde(s) en diegene wat deel is van die ondersoekliggaam. En juis omdat die tug plaasvind onder die gelowiges as geregverdigdes, maar sondaars, speel lewenswysheid en mensekennis by die ondersoekers ook 'n belangrike rol.

Die vierde oorweging waarom die kerklike tug van 'n geestelike aard moet wees, is omdat die kerklike tughandeling gemeenregtelik 'n quasi-judisiële handeling is en daarom billik en regverdig moet wees. Die ervaring van reg en geregtigheid in 'n geloofsverband is 'n geestelike ervaring. Net so is versoening onder mense en die herstel van die geloofseenheid en - vertroue onder Christengelowiges altyd 'n geestelike aksie. 
As 'n geestelike aksie onder leiding van die Gees van God waarin die menslike toepassers van die kerklike tughandeling glo aan die doel daarvan as 'n geestelike handeling, beskik hierdie tughandeling oor groot geestelike krag...

\section{Bibliografie}

Bouwman, H 1985. Gereformeerd Kerkrecht II. Kampen: De Groot Goudriaan.

Coertzen, P 1998. Church and order. Leuven: Peeters.

Du Plooy, A le R 2007. Beginsels vir regspraak in die kerk. Die Kerkblad April 2007, 18-20.

Engelhard, DH en Hofman, LJ 2001. Manual of Christian Reformed Church Government. Grand Rapids: CRC Publications.

Jansen, J 1952. Korte verklaring van de Kerkorde der Gereformeerde Kerken. Kampen: Kok.

Jansen, J sa. De Kerkelijke tucht. Handleiding ten dienste van de Gereformeerde Kerken. Nijverdal: Bosch.

Jonker, WD 1960. Die bevoegdheid van die streeksinodes in die nuwe konsepkerkorde. NGTT, Maart 1960, 33-37.

Jonker, WD 1994. Bevrydende waarheid. Wellington: HugenoteUitgewers.

Kruger, LS, Du Plessis, HLM, Spoelstra, B en Spoelstra, TT (gebruik as Kruger et al). Handleiding by die Kerkorde van die Gereformeerde Kerk in Suid-Afrika. Potchefstroom: Pro Rege.

Kuiper, BK 1995. The church in history. Grand Rapids: Eerdmans.

Kuyper, HH sa. De post acta of na-handelingen van de Nationale Synode van Dordtrecht in 1618 en 1619 gehouden. Amsterdam: Höveker en Wormser.

Nauta, D 1971. Verklaring van de Kerkorde van de Gereformeerde Kerken in Nederland. Kampen: Kok. 
Ned Geref Kerk 1964. Die Kerkorde. Kaapstad: NG Kerk-Uitgewers.

Ned Geref Kerk 2002. Die Kerkorde. Wellington: Lux Verbi.BM.

Ned Geref Kerk 2013. Die Kerkorde. Algemene Sinode.

NGK-Uitgewers III 1982. Die Drie Formuliere van Eenheid en ekumeniese belydenisse. Kaapstad: NGK-Uitgewers.

Plomp, J 1969. De kerkelijke tucht bij Calvijn. Kampen: Kok.

Pont, AD 1981. Die historiese agtergronde van ons kerklike reg. Pretoria: HAUM.

Rutgers, FL 1971. De geldigheid van de oude kerkenordening van die Nationale van Dortrecht van 1618-1619. Amsterdam: Ton Bolland.

Sadler, THN 1979. Die kerklike tughandeling. Pretoria: NG Kerkboekhandel van Transvaal.

Sizoo, A sa. Johannes Calvijn Institutie III. Delft: Meinema.

Strauss, PJ 2010. Kerk en orde vandag. Bloemfontein: Sunmedia.

Strauss, PJ 2015. Gereformeerdes onder die Suiderkruis 1652-2011. Bloemfontein: Sunmedia.

Smit, DJ 2009. Essays on being Reformed (3). Stellenbosch: Sunmedia.

Van Dellen. I en Monsma, M 1967. The revised church order commentary. Grand Rapids: Zondervan.

Visser, J 1999. Die Kerkorde in praktyk. Orkney: EFJS.

Vorster, JD 1960. Die Kerkorde vir die Ned Geref Kerke: besware daarteen en betekenis daarvan. NGTT, Sep 1960. 12-18. 